\title{
Insights into the Neutralization and DNA Binding of Toxin-Antitoxin System ParEso-CopAso by Structure-Function Studies
}

\author{
Juan Zhou ${ }^{1}$, Xue-Jian Du ${ }^{1}$, Ying Liu ${ }^{2}$, Zeng-Qiang Gao ${ }^{2}$, Zhi Geng ${ }^{2}$, Yu-Hui Dong ${ }^{2,3, *}$ and Heng Zhang ${ }^{2, *}$ \\ 1 Institute of Health Sciences and School of Life Science, Anhui University, Hefei 230601, China; \\ zhoujuan@ihep.ac.cn (J.Z.); duxuejian@ihep.ac.cn (X.-J.D.) \\ 2 Beijing Synchrotron Radiation Facility, Institute of High Energy Physics, Chinese Academy of Sciences, \\ Beijing 100049, China; yingliu@ihep.ac.cn (Y.L.); gaozq@ihep.ac.cn (Z.-Q.G.); gengz@ihep.ac.cn (Z.G.) \\ 3 University of Chinese Academy of Sciences, Beijing 100049, China \\ * $\quad$ Correspondence: dongyh@ihep.ac.cn (Y.-H.D.); zhangheng@ihep.ac.cn (H.Z.); Tel.: +86-10-8823-3090 (Y.-H.D.); \\ $+86-10-8823-4028$ (H.Z.)
}

Citation: Zhou, J.; Du, X.-J.; Liu, Y.; Gao, Z.-Q.; Geng, Z.; Dong, Y.-H.; Zhang, H. Insights into the Neutralization and DNA Binding of Toxin-Antitoxin System ParEso-CopAso by Structure-Function Studies. Microorganisms 2021, 9, 2506. https://doi.org/10.3390/ microorganisms 9122506

Academic Editors: Camilla Lazzi and Claudia Folli

Received: 31 August 2021

Accepted: 27 November 2021

Published: 3 December 2021

Publisher's Note: MDPI stays neutral with regard to jurisdictional claims in published maps and institutional affiliations.

Copyright: (C) 2021 by the authors Licensee MDPI, Basel, Switzerland. This article is an open access article distributed under the terms and conditions of the Creative Commons Attribution (CC BY) license (https:/ / creativecommons.org/licenses/by/ $4.0 /)$.

\begin{abstract}
ParE $\mathrm{SO}_{\mathrm{SO}}-\mathrm{CopA}_{\mathrm{SO}}$ is a new type II toxin-antitoxin (TA) system in prophage CP4So that plays an essential role in circular CP4So maintenance after the excision in Shewanella oneidensis. The toxin ParESO severely inhibits cell growth, while CopA $A_{S O}$ functions as an antitoxin to neutralize ParESO toxicity through direct interactions. However, the molecular mechanism of the neutralization and autoregulation of the TA operon transcription remains elusive. In this study, we determined the crystal structure of a ParE $\mathrm{SO}_{-}-\mathrm{CopA}_{\mathrm{SO}}$ complex that adopted an open V-shaped heterotetramer with the organization of ParE $\mathrm{SO}_{-}\left(\mathrm{CopA}_{\mathrm{SO}}\right)_{2}-\mathrm{ParE}_{\mathrm{SO}}$. The structure showed that upon ParE $\mathrm{SO}_{\mathrm{S}}$ binding, the intrinsically disordered C-terminal domain of CopA $A_{S O}$ was induced to fold into a partially ordered conformation that bound into a positively charged and hydrophobic groove of ParE $\mathrm{S}_{\mathrm{SO}}$. Thermodynamics analysis showed the DNA-binding affinity of CopAsO was remarkably higher than that of the purified TA complex, accompanied by the enthalpy change reversion from an exothermic reaction to an endothermic reaction. These results suggested ParE $\mathrm{SO}_{\mathrm{O}}$ acts as a de-repressor of the TA operon transcription at the toxin:antitoxin level of 1:1. Site-directed mutagenesis of ParESO identified His91 as the essential residue for its toxicity by cell toxicity assays. Our structure-function studies therefore elucidated the transcriptional regulation mechanism of the ParESO-CopA $\mathrm{A}_{\mathrm{SO}}$ pair, and may help to understand the regulation of CP4So maintenance in S. oneidensis.
\end{abstract}

Keywords: toxin-antitoxin; ParE toxin; neutralization mechanism; crystal structure

\section{Introduction}

Toxin-antitoxin (TA) loci are usually small genetic modules that are widespread in bacterial plasmids or chromosomes, and are typically composed of adjacent toxin and antitoxin genes encoding in operons. TA systems may regulate cell growth and death by targeting various cellular functions $[1,2]$. TA systems can be characterized into six different types (types I-VI) based on the interaction mode of the TA and the molecular nature of the antitoxin [3]. A group of type VII TA systems was recently discovered in several species [4], such as Mycobacterium tuberculosis [5] and Shewanella oneidensis [6], in which the antitoxins enzymatically neutralize toxins.

Type II TA is the most well-characterized and abundant system that is widely distributed in bacterial genomes and plasmids [3]. In type II TA systems, both the toxin and the antitoxin are proteins with small molecular weights, and the antitoxin can directly bind and neutralize the toxicity of the cognate toxin during normal growth by forming a tight protein-protein complex. The type II antitoxins are generally composed of a usually intrinsically disordered DNA-binding domain and a neighboring toxin-neutralizing domain [7]. 
The DNA-binding domain can bind to its own promoter region of the TA operon to autoregulate its transcription. The RelE/ParE superfamily is a prevalent toxin family that contains a conserved protein fold but a very low sequence conservation [8-10]. With the exception that Escherichia coli ParE2 did not inhibit DNA gyrase and M. tuberculosis ParE2 interacted weakly with GyrB [11,12], most ParE toxins are characterized as the inhibitors of bacterial gyrase by interacting with the GyrA subunit. They can inhibit gyrase-mediated supercoiling and therefore cause the accumulation of DNA breaks [13]. Distinctly from ParE toxins, the RelE subfamily toxins (such as RelE, YoeB, and HigB) function as ribosome-dependent ribonucleases [14-16]. They can cleave mRNA in a translation-dependent fashion to stall the ribosome $[17,18]$.

The proteins SO_1444 (ParE $\left.\mathrm{SO}_{\mathrm{S}}\right)$ and SO_1445 (CopA $\left.\mathrm{SO}_{\mathrm{SO}}\right)$ in the CP4 $4_{\text {So }}$ prophage from Shewanella oneidensis were recently characterized as a typical type II TA pair, with an important role in $\mathrm{CP}_{\mathrm{So}}$ maintenance after its excision in host cells [19]. The toxin ParE $\mathrm{E}_{\mathrm{SO}}$ can severely inhibit cell growth and cause filamentous growth. The antitoxin CopAso can neutralize ParESO toxicity by direct and tight protein-protein binding. CopAsO can bind to a DNA motif in the promoter region containing two inverted repeats (5'-GTANTAC $(\mathrm{N})_{3}$ GTANTAC $-3^{\prime}$ ) to repress the transcription of the TA operon. CopAso can also bind to a highly similar DNA motif in the promoter region of another TA system, $\mathrm{PemK}_{\mathrm{SO}} / \mathrm{PemI} \mathrm{SO}_{\mathrm{SO}}$ in megaplasmid pMR-1 of $S$. oneidensis to repress its transcription. The following NMR studies indicated CopA $\mathrm{A}_{\mathrm{SO}}$ has an ordered N-terminal domain and an intrinsically disordered C-terminal domain [20]. Crystal structure of the N-terminus showed it exhibits typical characteristics of ribbon-helix-helix (RHH) antitoxins for DNA binding. It was further speculated that the DNA binding of the N-terminal domain can be facilitated by the C-terminal domain, and such facilitation may further induce the fold and association of the C-terminal domain. The results indicated that DNA binding in the N-terminal domain will allosterically induce the disordered C-terminal domain to fold, which may further promote its self-association [20].

In spite of the above preliminary study on $\mathrm{CopA}_{\mathrm{SO}}$, the inhibition mechanism of

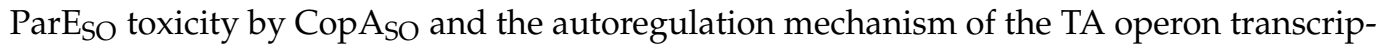
tion remain uncharacterized. In this work, we performed the structure-function studies on ParE $\mathrm{SO}_{-}-\mathrm{CopA}_{\mathrm{SO}}$ system and demonstrated how the ParE $\mathrm{SO}_{\mathrm{SO}}$ was recognized and inhibited by CopAso. The promoter DNA-binding character of the antitoxin and essential residues for the toxicity of the toxin were also investigated. These findings revealed the neutralization mechanism of the ParE $\mathrm{SO}_{\mathrm{SO}}-\mathrm{CopA}_{\mathrm{SO}} \mathrm{TA}$ pair, and helped to understand the autoregulation mechanism of this TA operon transcription.

\section{Materials and Methods}

\subsection{Construction of Plasmids and Bacterial Strains}

The recombinant plasmid pET28b expressing ParE $\mathrm{SO}_{\mathrm{SO}}-\mathrm{Cop}_{\mathrm{SO}}$ complex or CopA $\mathrm{A}_{\mathrm{SO}}$ was constructed as previously described [19]. The recombinant plasmid was transformed into an E. coli BL21(DE3) pLysS expression strain (Invitrogen, Waltham, MA, USA), for the expression and purification used in crystallization and DNA-binding studies. The gene encoding $\operatorname{cop} A_{S O}-p a r E_{S O}$ or parE $E_{S O}$ was cloned into pBAD18 by the method as described previously [21]. The pBAD18-based plasmids expressing ParESO-CopAsO or ParESO (wild-type and mutants) were transformed into E. coli K-12 strain TY0807 (sup araD139 $^{0}$ $h s d R \Delta l a c X 74 \mathrm{rpsL} \mathrm{araD}^{+}$). These strains were grown in the presence of arabinose for cell toxicity assays. Site-directed mutagenesis of par $E_{S O}$ or cop $A_{S O}$ was performed by a PCR-based technique according to the QuickChange site-directed mutagenesis strategy (Stratagene, San Diego, CA, USA) following the manufacturer's instructions. The mutant genes were sequenced and found to contain only the desired mutations.

\subsection{Protein Expression and Purification}

Bacterial cells harboring pET28b-ParE $\mathrm{SO}_{-}-\mathrm{CopA}_{\mathrm{SO}}$ were grown to $\mathrm{OD}_{600 \mathrm{~nm}}$ of 0.6 in LB media at $37{ }^{\circ} \mathrm{C}$ in the presence of $50 \mathrm{mg} / \mathrm{mL}$ kanamycin. Induction of protein expression 
was initiated by adding isopropyl-1-thio- $\beta$-D-galactopyranoside (IPTG) to the culture to a final concentration of $1 \mathrm{mM}$, and cells were grown at $16^{\circ} \mathrm{C}$. Cells were pelleted after $18 \mathrm{~h}$ by centrifugation at $3500 \mathrm{rpm}$ for $35 \mathrm{~min}$ at $4{ }^{\circ} \mathrm{C}$. Cell pellets were suspended in the buffer containing $20 \mathrm{mM}$ Tris (pH 8.0), $250 \mathrm{mM} \mathrm{NaCl}, 10 \mu \mathrm{g} / \mathrm{mL}$ DNase, and $1 \mathrm{mM}$ $\beta$-mercaptoethanol ( $\beta$-ME). The cell suspension was disrupted by high-pressure homogenizer and then centrifuged at $16,000 \times g$ for $50 \mathrm{~min}$ at $4{ }^{\circ} \mathrm{C}$. The supernatant was then loaded onto a Ni-NTA column that was pre-equilibrated with $20 \mathrm{mM}$ Tris ( $\mathrm{pH} 8.0), 500 \mathrm{mM}$ $\mathrm{NaCl}, 10 \mathrm{mM}$ imidazole, and $1 \mathrm{mM} \beta$-ME buffer. The His-tagged protein was eluted in $20 \mathrm{mM}$ Tris (pH 8.0), $250 \mathrm{mM} \mathrm{NaCl}$, and $250 \mathrm{mM}$ imidazole. The complex was further purified by a Hitrap $Q$ column (GE Healthcare, Chicago, IL, USA) pre-equilibrated with $20 \mathrm{mM}$ Tris- $\mathrm{HCl}, 100 \mathrm{mM} \mathrm{NaCl}, 1 \mathrm{mM}$ dithiotheitol (DTT), $\mathrm{pH}$ 8.0, with a linear gradient of $100-1000 \mathrm{mM} \mathrm{NaCl}$ in $20 \mathrm{mM}$ Tris- $\mathrm{HCl} \mathrm{pH}$ 8.0. Next, the protein was purified by Superdex200 chromatography on an ÄKTA Prime system (GE Healthcare, USA) to obtain highly pure ParE $\mathrm{SO}_{\mathrm{S}}-\mathrm{CopA}_{\mathrm{SO}}$ complex. The gel filtration buffer contained $20 \mathrm{mM}$ Tris ( $\mathrm{pH} 8.0$ ), $100 \mathrm{mM} \mathrm{NaCl}$, and $1 \mathrm{mM}$ DTT. The eluted fractions in all purification steps were analyzed by sodium dodecyl sulfate-polyacrylamide gel electrophoresis (SDS-PAGE). CopA $\mathrm{SO}_{\mathrm{SO}}$ was overexpressed and purified using the same procedures described above.

The selenomethionine (Se-Met) ParE $\mathrm{SO}_{\mathrm{SO}}-\mathrm{CopA}_{\mathrm{SO}}$ complex was produced in minimal medium supplemented with $100 \mathrm{mg}$ per liter lysine, phenylalanine, and threonine; and $50 \mathrm{mg}$ per liter isoleucine, leucine, valine, and selenomethionine. The Se-Met protein production and purification were the same as described above.

\subsection{Protein Crystallization and Structure Determination}

The purified complex was concentrated to $\sim 10 \mathrm{mg} / \mathrm{mL}$ using a Millipore Amicon Ultra apparatus. The initial crystallization conditions were obtained through utilization of several sparse matrix screens (Hampton Research, Aliso Viejo, CA, USA) with the sitting drop vapor diffusion method at room temperature after 2-3 days. Crystal quality was optimized by adjusting the concentration of the precipitant and buffer. The best crystal of ParE SO-CopA $_{\text {SO }}$ complex was obtained in a solution of $20 \%$ PEG3350 and $0.2 \mathrm{M}$ tri-sodium citrate at $20{ }^{\circ} \mathrm{C}$. The crystals were soaked in the reservoir solution supplemented with $15 \%$ $(v / v)$ glycerol for a few seconds and then flash-frozen in liquid nitrogen. The diffraction data from a single crystal of a selenomethionine-substituted protein were collected on the beamline station BL19 U of the Shanghai Synchrotron Radiation Facility (SSRF) using+ a Pilatus $6 \mathrm{M}$ detector at a wavelength of $0.9788 \AA$. The total oscillation was $360^{\circ}$ with $1^{\circ}$ per image, and the exposure time was $1 \mathrm{~s}$ per image.

All the data were processed by HKL2000 [22]. The Se-Met crystal structure of the ParE $\mathrm{SO}_{\mathrm{SO}} \mathrm{Cop} \mathrm{A}_{\mathrm{SO}}$ complex was determined by the single-wavelength anomalous dispersion method. The selenium atoms were located by the program Shelxd and then used to calculate the initial phases in Shelxe [23]. The phases from Shelxe were improved in Resolve [24] and then used in Buccaneer [25] for model building. All structures above were refined with the program Phenix.refine [26] and manually corrected in Coot [27]. The qualities of the final models were validated with the program MolProbity [28]. Refinement statistics and model parameters are given in Table 1. The program PyMOL (http:/ /www.pymol. sourceforge.net) was used to prepare structural figures. 
Table 1. X-ray data collection and refinement statistics.

\begin{tabular}{|l|l|}
\hline Data Collection & ParE $_{\text {SO-CopA }}$ SO Complex (Se-Met) \\
\hline Beamline & SSRF 17U1 \\
\hline Wavelength $(\AA)$ & 0.9788 \\
\hline Space group & $P 4{ }_{3} 2{ }_{1} 2$ \\
\hline Unit-cell parameters & $\mathrm{a}=85.4 \AA, \mathrm{b}=85.4 \AA, \mathrm{c}=110.9 \AA, \alpha=\beta=\gamma=90^{\circ}$ \\
\hline Resolution $(\AA)$ & $3.80(3.87-3.80)^{\mathrm{a}}$ \\
\hline Number of unique reflections & $7720(375)$ \\
\hline Completeness $(\%)$ & $100(99.7)$ \\
\hline Redundancy & $20.3(22.8)$ \\
\hline Mean I/o $(\mathrm{I})$ & $25.0(7.2)$ \\
\hline Molecules in asymmetric unit & 4 \\
\hline $\mathrm{R}_{\text {merge }}(\%)$ & $19.4(69.6)$ \\
\hline $\mathrm{R}_{\text {meas }}(\%)$ & $19.7(71.2)$ \\
\hline CC $1 / 2$ & $100(98.2)$ \\
\hline Structure Refinement & \\
\hline Reflections used in refinement & 7667 \\
\hline Resolution range $(\AA)$ & $33.93-3.80$ \\
\hline $\mathrm{R}_{\text {work }} / \mathrm{R}_{\text {free }}(\%)$ & $29.8 / 30.5$ \\
\hline Protein atoms & 2618 \\
\hline Protein residues & 312 \\
\hline Average B factor $\left(\AA^{2}\right)$ & 133.8 \\
\hline Ramachandran plot $(\%)$ & \\
\hline Most favored & 90.1 \\
\hline Allowed & 6.6 \\
\hline Disallowed & 3.6 \\
\hline R.m.s. deviations & \\
\hline Bond lengths $(\AA)$ & 0.005 \\
\hline Bond angles $\left({ }^{\circ}\right)$ & 0.806 \\
\hline
\end{tabular}

a The values in parentheses are those for the highest resolution shell.

\subsection{Isothermal Titration Calorimetry (ITC)}

ITC was applied to quantitatively determine the binding affinity of the $\mathrm{ParE}_{\mathrm{SO}^{-}}$ CopA $_{S O}$ complex or CopA $A_{S O}$ to a 25 bp DNA duplex derived from the $\operatorname{cop} A_{S O}-p a r E_{S O}$ promoter ( $5^{\prime}$-TAAGGTATTACCTAGTAGTACTAAG-3'; the palindromic sequences are underlined). For the titration experiments, the protein was purified using the same method as above and was dialyzed against the buffer containing $20 \mathrm{mM}$ Tris ( $\mathrm{pH} 8.0), 100 \mathrm{mM}$ $\mathrm{NaCl}$, and $5 \%(v / v)$ glycerol for $24 \mathrm{~h}$. DNA was dissolved in the same buffer as above. The ITC experiments were carried out using a high-sensitivity iTC-200 microcalorimeter from Microcal (GE Healthcare) at $20^{\circ} \mathrm{C}$ using 100-400 $\mu \mathrm{M}$ DNA in the injector with 10-100 $\mu \mathrm{M}$ ParE $\mathrm{SO}_{\mathrm{SO}}-\mathrm{CopA}_{\mathrm{SO}}$ complex or CopAsO in the sample cell. All samples were thoroughly degassed and then centrifuged to get rid of precipitates. Injection volumes of $2 \mu \mathrm{L}$ per injection were used for the different experiments, and for every experiment, the heat of dilution for each ligand was measured and subtracted from the calorimetric titration experimental runs for the protein. Consecutive injections were separated by $2 \mathrm{~min}$ to allow the peak to return to the baseline. Integrated heat data obtained for the ITCs were fitted in a one-site model using a nonlinear least-squares minimization algorithm to a theoretical titration curve, using the MicroCal-Origin 7.0 software package.

\subsection{Cell Toxicity Assay}

E. coli K-12 cells harboring pBAD18-cop $A_{S O}$-parE $E_{S O}$ (CopAsO wild-type or mutants) or pBAD18-parE $E_{S O}$ (ParE $E_{S O}$ wild-type or mutants) were grown in Luria-Bertani (LB) medium containing ampicillin $(50 \mu \mathrm{g} / \mathrm{mL})$ with or without $0.1 \%$ L-arabinose. Optical densities at $660 \mathrm{~nm}\left(\mathrm{OD}_{660 \mathrm{~nm}}\right)$ were measured every $2 \mathrm{~h}$ for individual cell cultures. Triplicate measurements were performed, and similar results were obtained for each measurement unless stated. The samples of the cells expressing His-tagged ParE $\mathrm{SO}_{\mathrm{SO}}$ wild-type and variants 
were collected at $8 \mathrm{~h}$, and their expression levels were examined by Western blot using antiHis antibodies. Each sample was lysed by ultrasonification to obtain soluble components after centrifugation. The total protein concentration was determined using the Bio-Rad protein-assay kit to confirm equal loading of lysate in each lane.

\section{Results}

\subsection{ParE $E_{S O}-C_{O} A_{S O}$ Complex Has an Open V-shaped Structure}

The crystal structure of the ParE $\mathrm{SO}_{\mathrm{SO}}-\mathrm{CopA}_{\mathrm{SO}}$ complex was determined by the singlewavelength anomalous dispersion (SAD) method using a Se-Met-labeled protein. The structure belonged to the space group $P 4_{3} 2_{1} 2$, and was refined to a final $R / R_{\text {free }}$ factor of 0.29/0.30 at $3.80 \AA$ A resolution (Table 1). There was a CopA $A_{S O}$ homodimer binding two respective ParE $\mathrm{SO}_{\mathrm{SO}}$ molecules in an asymmetric unit (ASU). The resulting heterotetramer adopted an overall very open, $\mathrm{V}$-shaped architecture with the organization of $\mathrm{ParE}_{\mathrm{SO}^{-}}$ $\left(\mathrm{CopA}_{\mathrm{SO}}\right)_{2}-\mathrm{ParE} \mathrm{ES}_{\mathrm{SO}}$ (Figure 1a). The electron densities of the main chains in the overall structure, especially the C-terminus of CopAso (Figure 1c), could be well traced at moderate resolution.

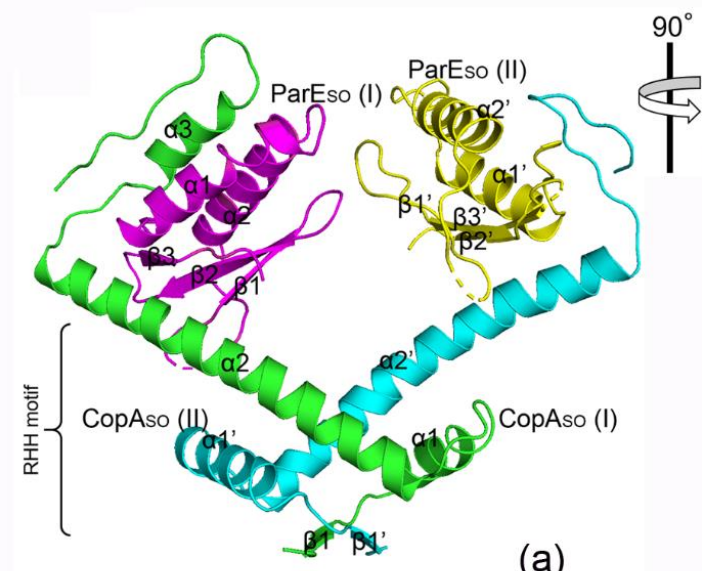

(a)

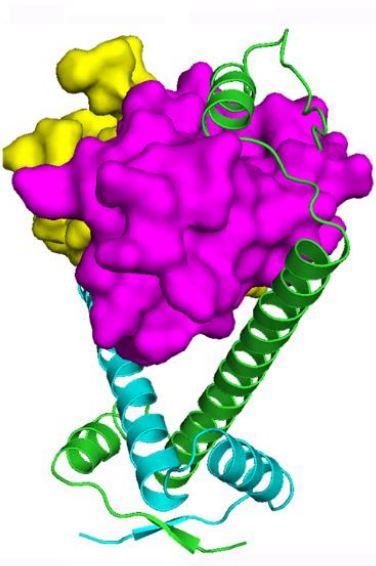

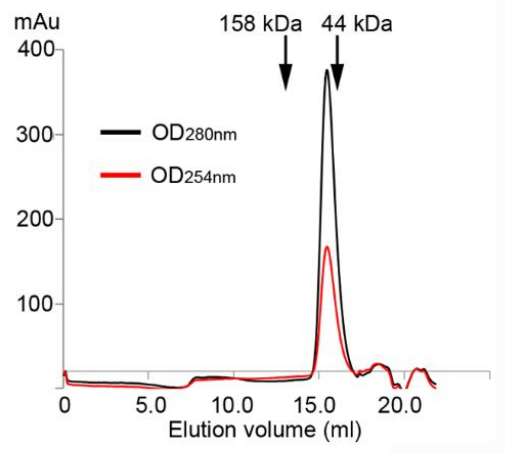

(b)

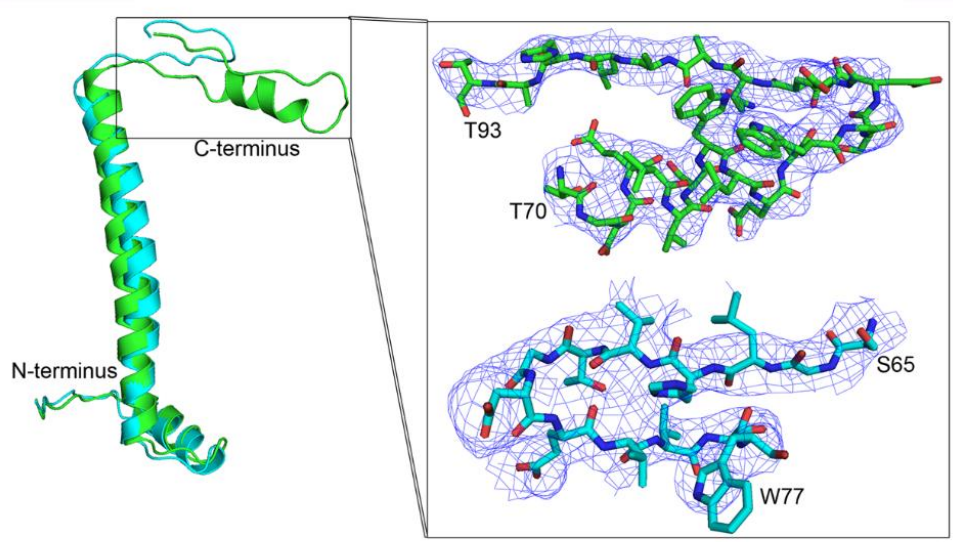

(c)

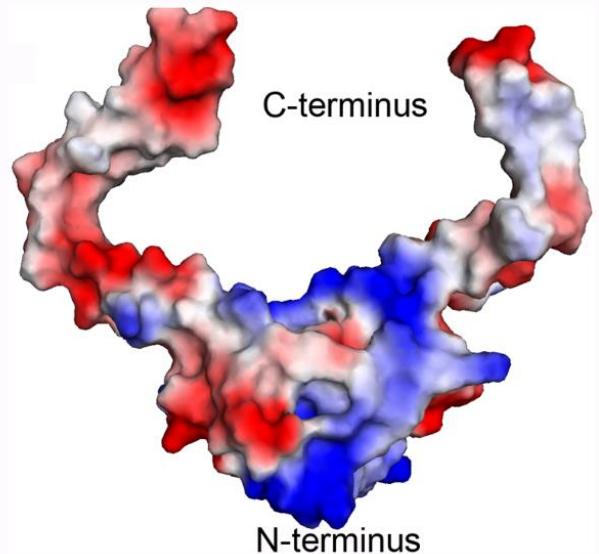

(d)

Figure 1. Overview of the crystal structure of the ParE $\mathrm{SO}_{-}-\mathrm{CopA}_{\mathrm{SO}}$ complex. (a) Overall structure of V-shaped ParE $\mathrm{SO}^{-}$ $\left(\mathrm{CopA}_{\mathrm{SO}}\right)_{2}-\mathrm{ParE} \mathrm{SO}_{\mathrm{SO}}$ heterotetramer. The two CopA $\mathrm{SO}_{\mathrm{SO}}$ molecules (I and II) are shown in cyan and green, respectively; whereas the two ParE $\mathrm{SO}_{\mathrm{SO}}$ molecules (I and II) are shown in magenta and yellow, respectively. ParE $\mathrm{SO}_{\text {and CopA }}$ are shown as illustrations, except that ParE $E_{S O}$ is shown as a surface in the right panel. (b) Estimation of the oligomeric state of the ParE $_{\mathrm{SO}}-\mathrm{CopA}_{\mathrm{SO}}$ complex in solution using size-exclusion chromatography (Superdex ${ }^{\mathrm{TM}} 200$ 10/300 GL). The purified complex was eluted from the chromatogram column at $\sim 15.0 \mathrm{~mL}$. (c) Structural superimposition of two CopAsO molecules in this complex. An electron density map $(2 \mathrm{Fo}-\mathrm{FC})$ of the C-terminal regions of CopA $\mathrm{SO}$ (I) (residues G66-T93) and CopA (II) (residues G66-W77) is shown at a $2.0 \sigma$ level. (d) The molecular surface representation of CopAsO (blue, +6.9KT; red, $-6.9 \mathrm{KT}$ ), colored according to its local electrostatic potential. The N-terminal and C-terminal domains are distributed with predominantly positive and negative charges, respectively. 
To determine the functional assembly of the ParE $\mathrm{SO}_{\mathrm{SO}}-\mathrm{CopA}_{\mathrm{SO}}$ complex, the oligomeric state of the purified complex in solution was estimated by gel filtration chromatography (Figure 1b). The complex migrated on size-exclusion chromatography with a similar elution volume to that of the marker protein (corresponding to a molecular mass of $\sim 44 \mathrm{kDa}$ ). This was very close to the theoretical molecular weight of the heterotetramer observed in the crystal structure $(\sim 45.8 \mathrm{kDa})$.These results indicated the oligomeric state of the complex in solution was largely consistent with the heterotetramer crystal structure.

\subsection{Cop $A_{S O}$ Adopts a Partially Folded C-Terminal Conformation upon ParE $E_{S O}$ Binding}

The antitoxin CopAsO is composed of an N-terminal RHH domain $(\beta 1, \alpha 1$, and extended $\alpha 2$ ) and a C-terminal toxin-binding domain ( $\alpha 3$ and the extended loop). The two neighboring CopAso molecules dimerize via the RHH domain to mediate the DNA binding. The characteristic intermolecular two-stranded antiparallel $\beta$-sheet $\left(\beta 1\right.$ and $\left.\beta 1^{\prime}\right)$ of the RHH motif is located in the dimer interface (Figure 1a). The C-terminus (helix $\alpha 2$ ) of $\mathrm{CopA}_{\mathrm{SO}}$ extends outward from the dimerization domain, making the two ParE $\mathrm{E}_{\mathrm{SO}}$ toxins between two largely helical domains are sequestered (Figure 1a). Notably, the intrinsically disordered C-terminal domain is induced to fold into a partially ordered conformation upon ParE $\mathrm{SO}_{\mathrm{SO}}$ binding. Moreover, the conformations of C-terminal extension in the two $\mathrm{CopA}_{\mathrm{SO}}$ molecules are distinct, and part of the extension is further folded into a helix $(\alpha 3)$ in CopA $A_{S O}$ (I) (Figure 1c). A surface-charge analysis of CopA $A_{S O}$ showed the $\mathrm{N}$-terminal and C-terminal domains were distributed with dominantly positive and negative charges, respectively, which was consistent with the DNA-binding and toxin-binding functions, respectively (Figure 1d).

A DALI search (http:/ / ekhidna.biocenter.helsinki.fi/dali_server) revealed the overall structure of CopAso did not show remarkable similarities with known structures, except the recently reported CopA $A_{S O} \mathrm{~N}$-terminal structure (1-50 aa, PDB ID: 6IYA) (DALI Z-score of 5.1 and an RMSD of $1.2 \AA$ ). Structural comparison of the full-length CopAso with the $\mathrm{N}$-terminal structure showed there were no remarkable changes in the RHH domain upon ParE $E_{S O}$ binding (Figure S1).

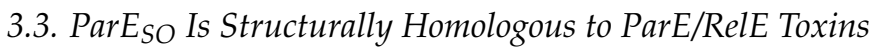

The toxin ParE $E_{S O}$ structure contains two N-terminal $\alpha$-helices $(\alpha 1-\alpha 2)$. The two helices form a hairpin tertiary structure that packs against the following three stranded antiparallel $\beta$-sheet ( $\beta 1-\beta 3$ ) (Figures $1 \mathrm{~b}$ and $2 \mathrm{a}$ ). The DALI search revealed that the overall structure of ParE $\mathrm{SO}$ had remarkable similarities with several ParE homologs from different species (PDB IDs: 5CEG, 3KXE, 5CW7, et al.) [9,12,29], with DALI Z-scores of 10.4-11.4 and RMSDs of 1.4-2.3 $\AA$, in spite of their low sequence identities ( $20 \%)$. In addition, ParE $E_{S O}$ also had structural similarities with several RelE superfamily members, such as YoeB, YafQ, and HigB (PDB IDs: 2A6Q, 4MMG, 3BPQ, et al.) [30-32], with DALI Z-scores of 7.7-8.9 and RMSDs of 2.4-3.1 $\AA$. In spite of the structural similarities of their overall structures, the conformations of several loops, including the $\alpha 2-\beta 1$ loop, $\beta 2-\beta 3$ loop, and C-terminal loop, were distinct from each other (Figure $2 \mathrm{~b}$ ). In particular, the C-terminal loop of ParE $\mathrm{SO}_{\mathrm{SO}}$ (His91) was directly involved in CopA $\mathrm{A}_{\mathrm{SO}}$ binding and played an important role associated with its toxicity (results below). 


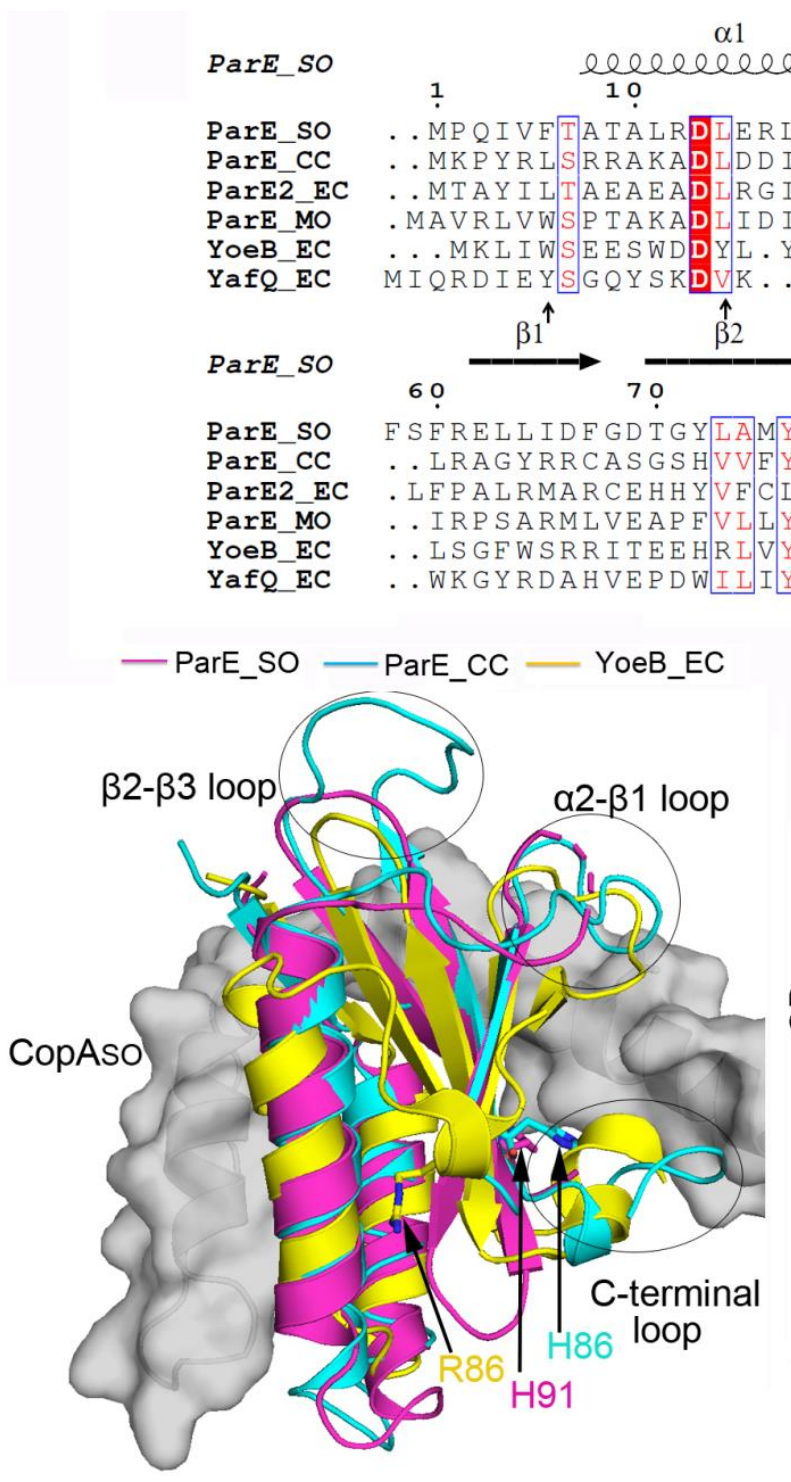

(b) $\alpha 2$

$$
\begin{aligned}
& \text { lebelebelebel } \\
& 30
\end{aligned}
$$

IINTIRK IESYPDI GRP I D N D

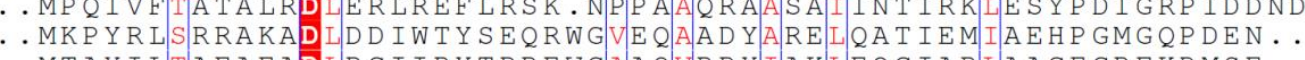

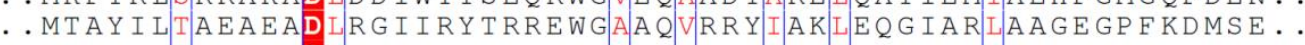
MAVRLVWSP TAKADLI D I YMI GSE. NIRAADRYYDQLEARALQLADQPRMGVRRPD. . .. MKLIWSEESWDDYL. YWQETDKR. IVKKINELIKDTRR . T PEEGKGKPEPLKHN .

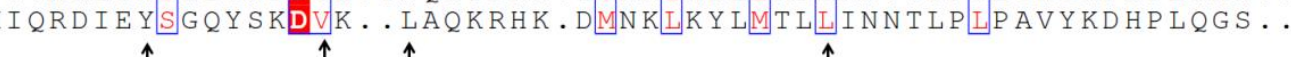

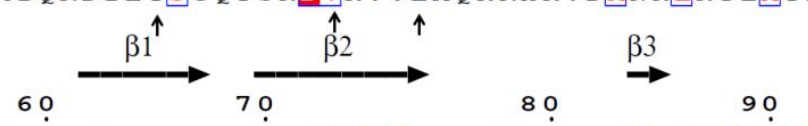

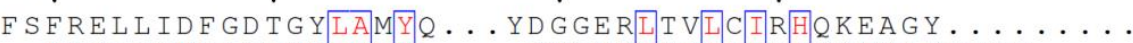

. LRAGYRRCASGSHVVFY . . . . RVGVRVIEIIRVILHQSMNARAHLG . . . .

. IRPSARMLVEAP FV L L Y E TVPDTDDGPVEWVEIVIR. VVDGRRD LNRLF .

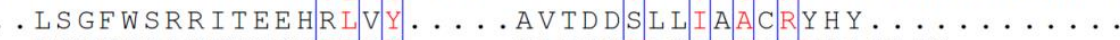

$\cdots . . . . . . . \cdots$

(a)

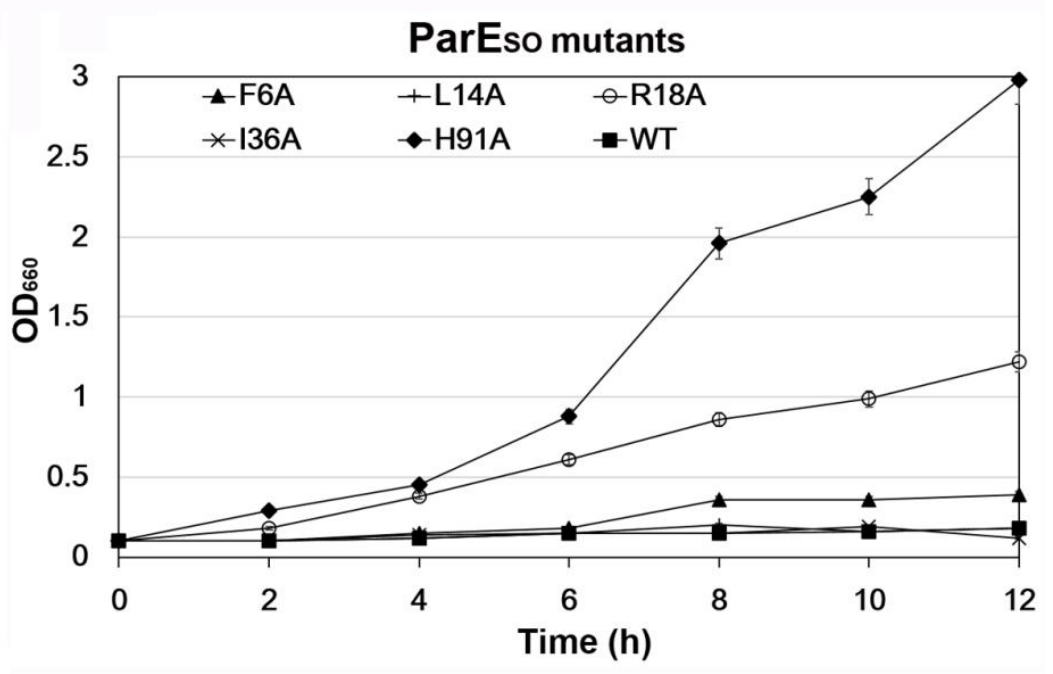

Time (h)

(c)

Figure 2. Identification of key residues involved ParE $E_{S O}$ toxicity. (a) Structure-based sequence alignment of ParE $E_{S O}$ with its representative homologs from different species performed using clustal X (version 1.81) and ESPript 3 (Robert and Gouet, 2014). The conserved residues are boxed in blue, identical conserved and low conserved residues are highlighted in red background and red letters, respectively. These homologs include ParE proteins from Mesorhizobium opportunistum (ParE_MO), Caulobacter crescentus (ParE_CC), and Escherichia coli O157 (ParE2_EC), as well as YoeB from Escherichia coli (YoeB_EC) and YafQ from E. coli (YafQ_EC). The CopAsO-binding residues mutated for the following cell toxicity assays are

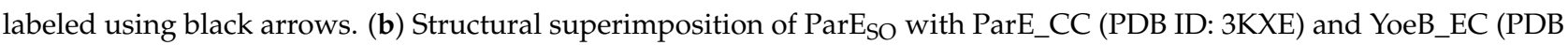
ID: 2A6Q). The major different regions are labeled using ellipses. The binding CopA $\mathrm{SO}_{\mathrm{S}}$ is shown as a gray surface. The critical residue His91 in ParESO and the corresponding residues His86/Arg86 in ParE_CC/YoeB_EC are shows as sticks. (c) Identification of key residues involved ParE $E_{S O}$ toxicity by cell toxicity assays. E. coli K-12 harboring pBAD18-parE (wild-type or mutants) were grown in LB medium containing $0.1 \%$ arabinose. Three independent experiments were conducted; error bars indicate standard error of mean $(n=3)$.

\subsection{The C-Terminal Extension of Cop $A_{S O}$ Binds into a Positive and Hydrophobic Groove of ParE $E_{S O}$}

Structural analysis showed that the toxin-antitoxin contacts were mainly mediated by the C-terminal domain ( $\alpha 3$ and C-terminus of $\alpha 2)$ of CopAsO and the two helices $(\alpha 1$ and $\alpha 2)$ of ParE $E_{S O}$ (Figure 3a,b). The buried surface area $\left(1082 \AA^{2}\right)$ of CopA $A_{S O}(I)$ at the interface was significantly larger than that of CopA $A_{S O}$ (II) $\left(580 \AA^{2}\right)$, which was $19.5 \%$, and 
$10.3 \%$ of the total surface area $\left(\sim 5600 \AA^{2}\right)$, respectively. The loss of buried surface area was likely caused by the more disordered C-terminus of CopAso (II), in which only 77 residues could be modeled compared to the 93 residues in CopAso (I) (Figure 1c). Remarkably, surface-charge analysis of CopA $\mathrm{AO}_{\mathrm{SO}}$ showed the C-terminal extension was predominantly distributed with negative charges (such as Glu54, Glu60, Glu61, and Glu86) (Figure 1d), which perfectly complemented positively charged regions in and around the binding grooves (such as Arg18, Arg22, and Arg90) (Figure 3c,d).

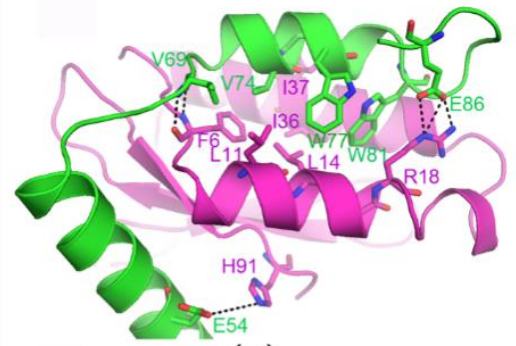

(a)

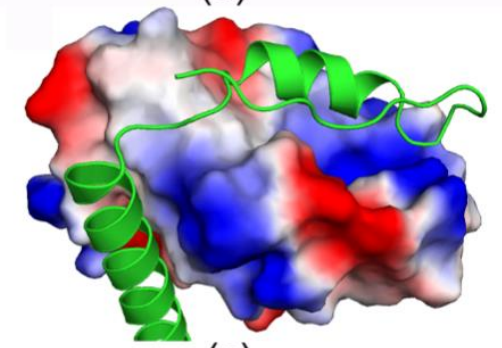

(c)

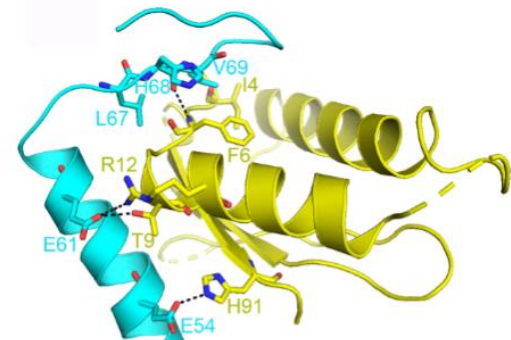

(b)

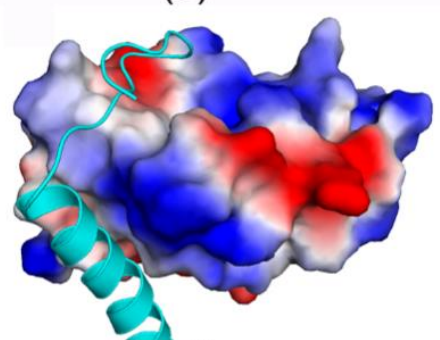

(d)

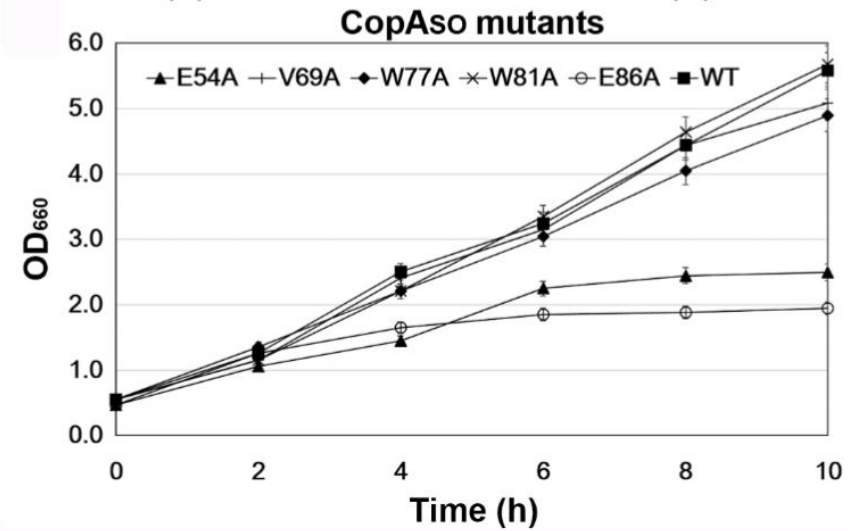

(e)

Figure 3. Contact analysis of ParE $\mathrm{SO}_{\mathrm{SO}}$ and $\mathrm{CopA}_{\mathrm{SO}}$ in the complex structure. (a,b) Detailed interaction analysis between ParE $\mathrm{SO}_{\mathrm{O}}$ and $\mathrm{CopA}_{\mathrm{SO}}$. CopA $\mathrm{A}_{\mathrm{SO}}$ made extensive contacts, including H-bonds, salt

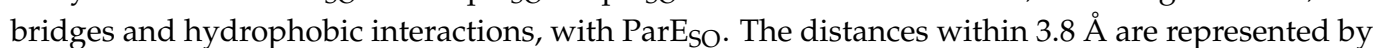

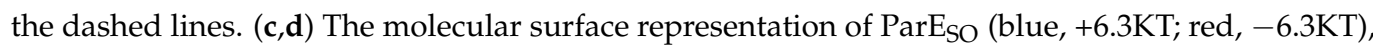
colored according to its local electrostatic potential. The C-terminus of CopAso were mainly distributed with negative charges (Figure 1d), which were well matched with the positive binding grove in ParE $\mathrm{SO}$. (e) Inhibitory effect of CopA $\mathrm{A}_{\mathrm{SO}}$ (wild-type or mutants) on ParE $\mathrm{SO}_{\mathrm{SO}}$ toxicity by determining E. coli growth. The CopA $\mathrm{SO}_{\mathrm{SO}}$ mutants E86A abolished their inhibition on ParE $\mathrm{SO}_{\mathrm{S}}$-mediated cell toxicity and resulted in a reduction in cell growth. Three independent experiments were conducted; error bars indicate standard error of mean $(n=3)$.

On the other hand, ParE $\mathrm{SO}_{\mathrm{O}}$ (I) and (II) were bound by the respective CopA $\mathrm{AO}_{\mathrm{SO}}$ at a slightly different angle $\left(\sim 15^{\circ}\right.$; Figure S2). Therefore, two ParE $E_{S O}$ molecules were not bound in a perfectly symmetric manner, as observed in common V-shaped TA structures such as ParD-ParE from Caulobacter vibrioides (PDB ID: 3KXE) and ParD3-ParE3 from 
Mesorhizobium opportunistum (PDB ID: 5CEG) [9,29]. The different binding angle of CopAsO toward ParE $\mathrm{SO}_{\mathrm{SO}}$ caused the specific contacts between the two ParE $\mathrm{SO}_{\mathrm{SO}}-\mathrm{CopA}_{\mathrm{SO}}$ pairs to be different. For example, the side chain of Glu86 in CopA $A_{S O}$ (I) can form three salt bridges with the side chain of Arg18. The main chain of Val69 in CopA $A_{S O}$ (I) can form two hydrogen bonds with the main chain of Phe6. The side chain of Glu61 in CopAsO (II) can form a salt bridge and a hydrogen bond with the side chain of Thr9 and Arg12, respectively. Moreover, a hydrogen bond between the side chain of Glu54 and the side chain of His91 is formed in both CopAso molecules. Moreover, the binding groove of ParESO also mediates significant hydrophobic contacts with the C-terminal extension of CopA $\mathrm{A}_{\mathrm{SO}}$ in both $\mathrm{ParE}_{\mathrm{SO}^{-}}$ CopA $_{S O}$ pairs. In particular, the hydrophobic patches in ParESO(I) are mainly composed of Phe6/Leu11/Leu14 in $\alpha 1$, and Ile36/Ile37 in $\alpha 2$. The two patches pack against the hydrophobic patch (Val69/Val74/Trp77/Trp81) of the C-terminal extension of CopAso(I). The hydrophobic contacts in the other TA pair are mediated between Leu67/Val69 in $\mathrm{CopA}_{\mathrm{SO}}$ (II) and Ile4/Phe6 in ParE $\mathrm{SO}_{\text {(II). }}$

In order to identify the key residues of CopAso in toxicity inhibition, the interacting residues were mutated to alanine to test their neutralization capacity by cell toxicity assays (Figure 3e). The results showed that mutation of the interacting residues (Val69, Trp77, and Trp81) in CopAso could repress the toxicity to allow normal cell growth similar to the wild-type (Figure 3e). The mutants E54A and E86A had a notable effect on ParE $\mathrm{SO}_{\mathrm{SO}}$ toxicity inhibition and caused a reduction in cell growth. Taken together, Glu54 and Glu86 were necessary for the inhibition of $\mathrm{ParE}_{\mathrm{SO}}$-mediated cell toxicity. The critical roles of the two residues were consistent with their multiple salt bridges/hydrogen bonds with ParE $E_{S O}$ observed in the structure. Moreover, the solvation energy $\left(\Delta^{\mathrm{i}} \mathrm{G}\right)$ of Glu54 and Glu86 is -0.19 and $-0.43 \mathrm{kcal} / \mathrm{mol}$, respectively, calculated from PISA analysis server (https://www.ebi.ac.uk/msd-srv/prot_int/pistart.html). Mutation of the two residues may greatly destabilize the interface and reduce the binding and inhibition of $\mathrm{ParE}_{\mathrm{SO}}$ by CopAso.

\subsection{H91 Is a Key Residue for ParE $S O$ Toxicity}

To investigate whether the CopAsO-binding residues in ParE $\mathrm{SO}_{\mathrm{SO}}$ are important for its cell toxicity, Phe6, Leu14, Arg18, Ile36, and His91 in ParE $E_{S O}$ were mutated to alanine. E. coli $\mathrm{K}-12$ cells harboring pBAD18-par $E_{S O}$ (wild-type or mutants) were grown in the presence of arabinose (Figure $2 \mathrm{c}$ and Figure S3). The effects of these mutants on cell growth were studied. The mutants F6A, L14A, and I36A exhibited a similar growth reduction to that of the wild-type, indicating they did not affect the toxicity of ParE $E_{S O}$. The mutant H91A showed a significantly high growth rate, whereas R18A had a moderate effect on the cell growth. These results showed mutation of His91 caused a significant loss of the toxicity of $\mathrm{ParE}_{\mathrm{SO}}$, and indicated that His91 was essential for the toxicity.

\subsection{DNA-Binding Capacity of Cop $A_{S O}$ Is Inhibited upon ParE $E_{S O}$ Binding}

CopA $_{\text {SO }}$ repressed the transcription of the TA operon by binding to a DNA motif in the promoter region containing two inverted repeats $\left(5^{\prime}\right.$-GTANTAC $(\mathrm{N})_{3}$ GTANTAC-3 $\left.{ }^{\prime}\right)$ [19]. We generated a $25 \mathrm{bp}$ DNA duplex corresponding to the promoter sequence containing the two inverted repeats, and explored the DNA-binding characteristics of CopAso by isothermal titration calorimetry (ITC) experiments (Figure 4). The results showed CopAso bound to the operator DNA fragment with a high affinity $\left(K_{D}=\sim 16 \mathrm{nM}\right)$, which was significantly higher than that of the purified CopAsO-ParESO complex $\left(K_{D}=\sim 660 \mathrm{nM}\right)$. More importantly, DNA binding of CopA $A_{S O}$ was an exothermic reaction $\left(\Delta \mathrm{H}=-1.72 \times 10^{4} \mathrm{M}^{-1} \mathrm{cal} / \mathrm{mol}\right)$ that was converted to an endothermic reaction $\left(\Delta \mathrm{H}=1.02 \times 10^{4} \mathrm{M}^{-1} \mathrm{cal} / \mathrm{mol}\right)$ upon ParE $\mathrm{SO}_{\mathrm{SO}}$ binding. The results suggested ParE $\mathrm{SO}_{\mathrm{SO}}$ repressed the DNA-binding capacity of CopA $\mathrm{A}_{\mathrm{SO}}$ when two ParE $E_{S O}$ molecules bound to a CopAso dimer (TA ratio 1:1) as observed in the above structure. The reversion of the enthalpy change $(\Delta \mathrm{H})$ indicated that significant conformational changes of the RHH domain of $\mathrm{CopA}_{\mathrm{SO}}$ may occur upon ParE $\mathrm{SO}_{\mathrm{SO}}$ binding. Meanwhile, CopAsO showed no detectable binding to the to the above $25 \mathrm{bp}$ DNA fragment, 
in which the palindromic sequences were completely destroyed (Figure S4). This indicated the two inverted repeats were required for $\mathrm{CopA}_{\mathrm{SO}}$-mediated transcriptional regulation.

\begin{tabular}{|c|c|c|c|c|}
\hline Proteins & $K_{\mathrm{D}}(\mathrm{nM})$ & $\Delta \mathrm{H}(\mathrm{kcal} / \mathrm{mol})$ & $\Delta \mathrm{S}(\mathrm{cal} / \mathrm{mol}$ degree $)$ & $\mathrm{N}$ \\
\hline CopAso & $16 \pm 1.2$ & $-17.22 \pm 0.47$ & -22.10 & $0.97 \pm 0.01$ \\
\hline ParEso-CopAso & $660 \pm 25.7$ & $10.19 \pm 0.43$ & -17.22 & $0.68 \pm 0.02$ \\
\hline
\end{tabular}

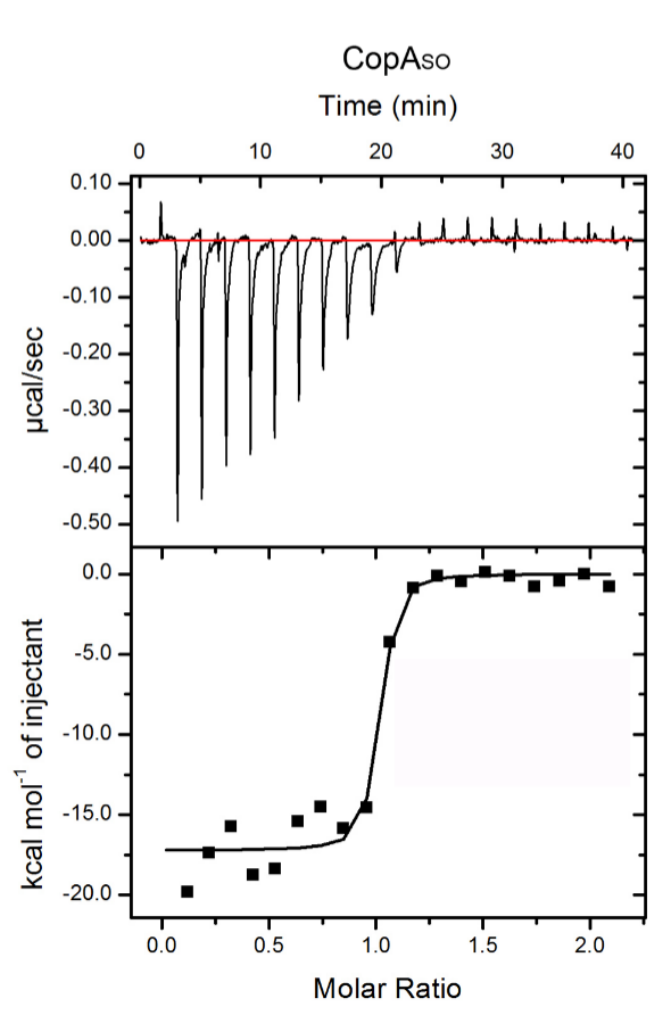

(a)

ParEso-CopAso

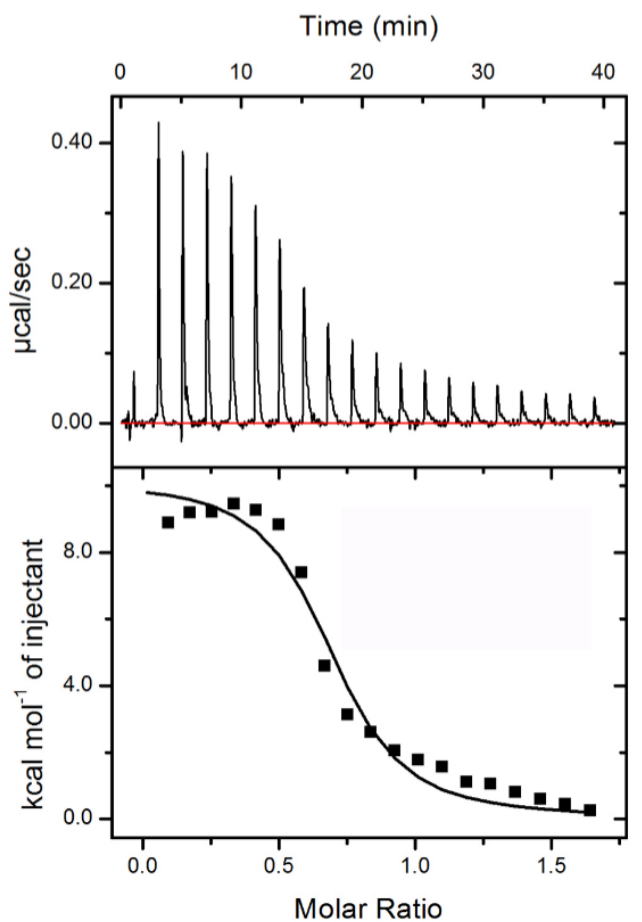

(b)

Figure 4. Thermodynamic analyses of $\mathrm{CopA}_{\mathrm{SO}}$ and the ParE $\mathrm{SO}_{\mathrm{SO}}-\mathrm{CopA}_{\mathrm{SO}}$ complex binding to the promoter DNA by ITC. (a) ITC data for titration of the proteins with the DNA fragment. $K_{\mathrm{D}}$, binding affinity; $\Delta \mathrm{H}$, change in enthalpy; $\Delta \mathrm{S}$, change in entropy; N, number of binding site. (b) ITC spectra for CopAsO and the ParEso-CopAso complex. Baseline subtracted raw ITC data for injections of DNA is indicated in the upper panels of each of the ITC profiles shown. The peaks normalized to the DNA/protein molar ratio were integrated as shown in the bottom panels. The solid dots indicate the experimental data, and the best fit to the experimental data was obtained from a nonlinear least squares method of fitting using a one-site binding model depicted by a solid line.

\section{Discussion}

In this study, the structure of the ParESO-CopA $\mathrm{A}_{\mathrm{SO}}$ complex revealed the TA pair is an open V-shaped heterotetramer. The intrinsically disordered C-terminal domain of CopAsO was induced to fold into a partially ordered conformation upon ParE $E_{S O}$ binding. Structurebased mutagenesis on the interacting residues in $\mathrm{ParE}_{\mathrm{SO}}$ and $\mathrm{CopA}_{\mathrm{SO}}$ revealed the essential residues involved in the toxicity and the neutralization by cell toxicity assays, respectively. Our cell toxicity assays revealed Glu54 and Glu86 in CopAso are necessary for the inhibition of ParEsO toxicity. Moreover, His91 and Arg18, which are the respective interacting residues of Glu54 and Glu86 in the complex structure, are important for ParEso toxicity.

Structure analysis of ParESO showed that compared to RelE superfamily members, it is more structurally homologous to the ParE superfamily, in spite of their low sequence 
identities $(\sim 20 \%)$. Moreover, ParE $\mathrm{SO}$ does not contain any of the three critical catalytic residues required for RNA cleavage on the ribosomes that are observed in the RelE family [17,18,30,31]. For example, the critical catalytic residues Glu46, Arg65, His83, and Tyr84, required for YoeB RNase activity [30], are not conserved in ParEsO (corresponding to Gly50, Leu73, Lys93, and Glu94, respectively) (Figure 2a). Therefore, like most ParE superfamily members [11,12,33], ParE $E_{S O}$ may function as an inhibitor of DNA gyrase, and this hypothesis requires experimental validation. Because expression of ParESO has severe inhibition on $S$. oneidensis or E. coli growth, we were not able to obtain recombinant soluble ParE $E_{S O}$ by its overexpression or by purifying from the Cop $\mathrm{A}_{\mathrm{SO}}-\mathrm{ParE} \mathrm{E}_{\mathrm{SO}}$ complex. A recent study on the antitoxin ParD2 structure from Vibrio cholerae (VcParD2) showed it had a similar organization to CopAsO, composed of the N-terminal ordered DNA-binding domain and the C-terminal intrinsically disordered protein (IDP) domain for ParE binding [34]. Moreover, in the absence of the IDP domain, VcParD2 was found to crystallize as a doughnut-shaped hexadecamer by the association of eight dimers. Analysis of the crystal packing of the N-terminal structure (1-50 aa, PDB ID: 6IYA) of CopAsO or the TA complex structure in this study showed no such architecture could be observed like that in VcParD2. Moreover, both the full-length protein and the N-terminal domain of CopASO are likely dimers in solution. However, oligomerization of the full-length VcParD2 can generate a stable, open decamer or dodecamer in solution, likely resulting from entropic pressure from the IDP tails.

The autoregulation of TA operons transcription in some type II TAs, such as Phd/Doc, RelBE, and CcdAB, is controlled by a mechanism known as conditional cooperativity $[7,35]$. The operator DNA-binding affinities are controlled by different ratios of toxin to antitoxin in the cell, and therefore affect the transcriptional repression level of the TA locus. When the toxin:antitoxin level is below 1:1 (excess antitoxin), the toxin can function as a co-repressor to prevent the antitoxin:DNA interaction and affect transcription. On the contrary, at higher ratios than 1:1 (excess toxin), the toxin may bind and physically destabilize the preformed TA-DNA complex. The toxin therefore can act as a de-repressor and increase the toxin expression level by activating the TA operon [1,3]. For example, the transcriptional repression level of relBE operon is found to be regulated by the overall RelB:RelE ratio both in vivo and in vitro, and the antitoxin RelB alone binds the operator DNA with a relatively low affinity [35]. However, the binding is dramatically stimulated at a RelB:RelE ratio of 2:1, whereas the DNA binding is lost at the ratio of more than 2:1 by the conditional cooperativity mechanism $[35,36]$. Our ITC analysis showed free CopAso had a high binding affinity to the operator DNA $\left(K_{\mathrm{D}}=\sim 16 \mathrm{nM}\right)$, whereas the binding was significantly inhibited $\left(K_{\mathrm{D}}=\sim 660 \mathrm{nM}\right)$ when binding by ParE $E_{\mathrm{SO}}$ at the 1:1 ratio. The results suggest that ParE $\mathrm{SO}_{\mathrm{S}}$ acted as a de-repressor rather than a co-repressor of the TA operon at the 1:1 ratio. On the contrary, at the $\mathrm{T}: \mathrm{A}=1: 1$ ratio, the DNA-binding capacity of HicA-HicB complex from Streptococcus pneumoniae was moderately higher than that of the antitoxin HicB dimer $\left(K_{\mathrm{D}}\right.$ from $\sim 8.8 \mu \mathrm{M}$ to $\left.\sim 4.2 \mu \mathrm{M}\right)$ [37]. This suggested that toxin HicA appeared to act as a co-repressor at the 1:1 ratio. Because we were not able to obtain recombinant ParESO $_{\mathrm{SO}}$ under present conditions, the DNA bindings of CopA $\mathrm{SO}_{\mathrm{SO}}$ in the presence of ParE $\mathrm{E}_{\mathrm{SO}}$ at different ratios were not determined. Further studies are required to determine whether the regulation of this TA operons transcription is controlled by conditional cooperativity. On the other hand, ParESO binding caused the enthalpy change $(\Delta \mathrm{H})$ reversion from an endothermic reaction to an exothermic reaction. The interaction changes due to hydrogen bond/salt bridge formation and van der Waals interactions may be reflected by binding enthalpy. The reversion of the enthalpy change indicated ParEso binding may induce significant conformational changes of RHH domains (such as the relative orientation) in the CopAsO dimer, which in turn impacts the molecular basis for interaction with DNA. Recent NMR studies indicated the C-terminal domain of CopA $\mathrm{A}_{\mathrm{SO}}$ alone was intrinsically disordered [20]. Here, our structure showed ParESO binding induced the C-terminal domain of CopAso to fold and associate into a partially ordered conformation, including the extended $\alpha 2$ in both CopAso molecules and $\alpha 3$ in one molecule. 
In summary, our structure-function studies demonstrated the neutralization mechanism of the ParE $\mathrm{SO}_{\mathrm{SO}}-\mathrm{Cop} \mathrm{A}_{\mathrm{SO}}$ system and identified the key residues involved in ParE $\mathrm{SO}_{\mathrm{SO}}$ toxicity. A previous study showed the repression of the mutated promoter (mutation of one or two inverted repeats) in the $\operatorname{par}_{S O}-\mathrm{cop} A_{S O}$ operon by $\mathrm{CopA}_{S O}$ was greatly reduced [19]. Here, we found free CopAso had distinct DNA-binding thermodynamic characteristics from the ParE $\mathrm{SO}_{\mathrm{S}}-\mathrm{CopA}_{\mathrm{SO}}$ complex. These biochemical studies are useful to understand the function of the ParE $\mathrm{SO}_{\mathrm{O}}-\mathrm{CopA}_{\mathrm{SO}}$ TA pair associated with the stabilizing prophage CP4So in S. oneidensis.

Supplementary Materials: The following are available online at https://www.mdpi.com/article/10 .3390 /microorganisms9122506/s1, Figure S1: Structural superimposition of CopA $A_{S O}$ derived from the complex with recently reported N-terminus (residues 1-49) of CopA $A_{S O}$. Figure S2: Structural superimposition of CopA $\mathrm{AS}_{\mathrm{SO}}$ (I) and (II) showing that their corresponding ParE $\mathrm{SO}_{\mathrm{SO}}$ molecules are bound at slightly different angles $\left(\sim 15^{\circ}\right)$. Figure S3. Western blot of lysate from wild-type cells expressing His-tagged ParE $\mathrm{SO}_{\mathrm{S}}$ variants. Figure $\mathrm{S} 4$. CopA $\mathrm{SO}$ binding to the mutated $25 \mathrm{bp}$ DNA duplex (5' TAAGGTATTACCTACCGGATGTAAG-3') by ITC.

Author Contributions: H.Z. and Y.-H.D. conceived and designed the experiments; J.Z., Y.L., X.-J.D. and Z.-Q.G., performed the experiments; X.-J.D., Z.G. and H.Z. analyzed the data; X.-J.D., H.Z. and Y.-H.D. wrote the paper. All authors have read and agreed to the published version of the manuscript.

Funding: This study was financially supported by grants from the National Basic Research Program of China (2017YFA0504900), the National Natural Science Foundation of China (31970152, U1732113, and 31670059), the Beijing Municipal Science \& Technology Commission (Z191100007219007), and the Strategic Priority Research Program of CAS (XDB37040302). The funders had no role in the design of the study; in the collection, analyses, or interpretation of data; in the writing of the manuscript; or in the decision to publish the results.

Institutional Review Board Statement: Not applicable.

Informed Consent Statement: Not applicable.

Data Availability Statement: The atomic coordinates and structure factors of the ParE $\mathrm{SO}_{\mathrm{SO}}-\mathrm{CopA}_{\mathrm{SO}}$ complex were deposited the RCSB Protein Data Bank with PDB code 7ETR.

Acknowledgments: We thank the staff of beamline station BL17U of the Shanghai Synchrotron Radiation Facility (SSRF) for providing technical support and for many fruitful discussions. We thank Xiaoxue Wang's lab at SCSIO, CAS for providing the recombinant plasmid for the ParESO-CopA $\mathrm{A}_{S O}$ expression.

Conflicts of Interest: The authors declare that the research was conducted in the absence of any commercial or financial relationships that could be construed as a potential conflict of interest.

\section{References}

1. Gerdes, K.; Christensen, S.K.; Løbner-Olesen, A. Prokaryotic toxin-antitoxin stress response loci. Nat. Rev. Genet. 2005, 3, 371-382. [CrossRef] [PubMed]

2. Yamaguchi, Y.; Inouye, M. Regulation of growth and death in Escherichia coli by toxin-antitoxin systems. Nat. Rev. Genet. 2011, 9, 779-790. [CrossRef]

3. Page, R.; Peti, W. Toxin-antitoxin systems in bacterial growth arrest and persistence. Nat. Chem. Biol. 2016, 12, 208-214. [CrossRef]

4. Wang, X.; Yao, J.; Sun, Y.C.; Wood, T.K. Type VII toxin/antitoxin classification system for antitoxins that enzymatically neutralize toxins. Trends Microbiol. 2021, 29, 388-393. [CrossRef] [PubMed]

5. Yu, X.; Gao, X.; Zhu, K.; Yin, H.; Mao, X.; Wojdyla, J.A.; Qin, B.; Huang, H.; Wang, M.; Sun, Y.C.; et al. Characterization of a toxinantitoxin system in Mycobacterium tuberculosis suggests neutralization by phosphorylation as the antitoxicity mech-anism. Commun. Biol. 2020, 3, 216. [CrossRef] [PubMed]

6. Yao, J.; Zhen, X.; Tang, K.; Liu, T.; Xu, X.; Chen, Z.; Guo, Y.; Liu, X.; Wood, T.K.; Ouyang, S.; et al. Novel polyadenylylationdependent neutralization mechanism of the HEPN/MNT toxin/antitoxin system. Nucleic Acids Res. 2020, 48, 11054-11067. [CrossRef]

7. Loris, R.; Garcia-Pino, A. Disorder- and Dynamics-Based Regulatory Mechanisms in Toxin-Antitoxin Modules. Chem. Rev. 2014, 114, 6933-6947. [CrossRef] 
8. Anantharaman, V.; Aravind, L. New connections in the prokaryotic toxin-antitoxin network: Relationship with the eukaryotic nonsense-mediated RNA decay system. Genome Biol. 2003, 4, R81. [CrossRef]

9. Dalton, K.M.; Crosson, S. A conserved mode of protein recognition and binding in a ParD-ParE toxin-antitoxin complex. Biochemistry 2010, 49, 2205-2215. [CrossRef]

10. Pandey, D.P.; Gerdes, K. Toxin-antitoxin loci are highly abundant in free-living but lost from host-associated prokaryotes. Nucleic Acids Res. 2005, 33, 966-976. [CrossRef]

11. Gupta, M.; Nayyar, N.; Chawla, M.; Sitaraman, R.; Bhatnagar, R.; Banerjee, N. The Chromosomal parDE2 Tox-in-Antitoxin System of Mycobacterium tuberculosis H37Rv: Genetic and Functional Characterization. Front. Microbiol. 2016, 7, 886. [CrossRef]

12. Sterckx, Y.G.J.; Jové, T.; Shkumatov, A.V.; Garcia-Pino, A.; Geerts, L.; De Kerpel, M.; Lah, J.; De Greve, H.; Van Melderen, L.; Loris, R. A unique hetero-hexadecameric architecture displayed by the Escherichia coli O157 PaaA2-ParE2 antitoxin-toxin complex. J. Mol. Biol. 2016, 428, 1589-1603. [CrossRef] [PubMed]

13. Jiang, Y.; Pogliano, J.; Helinski, D.R.; Konieczny, I. ParE toxin encoded by the broad-host-range plasmid RK2 is an inhibitor of Escherichia coli gyrase. Mol. Microbiol. 2002, 44, 971-979. [CrossRef] [PubMed]

14. Christensen, S.K.; Gerdes, K. RelE toxins from Bacteria and Archaea cleave mRNAs on translating ribosomes, which are rescued by tmRNA. Mol. Microbiol. 2003, 48, 1389-1400. [CrossRef] [PubMed]

15. Hurley, J.M.; Woychik, N.A. Bacterial toxin HigB associates with ribosomes and mediates translation-dependent mRNA cleavage at A-rich sites. J. Biol. Chem. 2009, 284, 18605-18613. [CrossRef] [PubMed]

16. Zhang, Y.; Inouye, M. The inhibitory mechanism of protein synthesis by YoeB, an Escherichia coli toxin. J. Bacteriol. 2009, 284, 6627-6638. [CrossRef] [PubMed]

17. Neubauer, C.; Gao, Y.-G.; Andersen, K.R.; Dunham, C.M.; Kelley, A.C.; Hentschel, J.; Gerdes, K.; Ramakrishnan, V.; Brodersen, D.E. The Structural Basis for mRNA Recognition and Cleavage by the Ribosome-Dependent Endonuclease RelE. Cell 2009, 139, 10841095. [CrossRef] [PubMed]

18. Pedersen, K.; Zavialov, A.; Pavlov, M.Y.; Elf, J.; Gerdes, K.; Ehrenberg, M. The Bacterial Toxin RelE Displays Codon-Specific Cleavage of mRNAs in the Ribosomal A Site. Cell 2003, 112, 131-140. [CrossRef]

19. Yao, J.; Guo, Y.; Wang, P.; Zeng, Z.; Li, B.; Tang, K.; Liu, X.; Wang, X. Type II toxin/antitoxin system ParESO/CopASO stabilizes prophage CP4So in Shewanella oneidensis. Environ. Microbiol. 2018, 20, 1224-1239. [CrossRef] [PubMed]

20. Zhao, R.; Li, Q.; Zhang, J.; Li, F.; Yao, J.; Zhang, J.; Liu, L.; Wang, X.; Zhang, X. Structure and allosteric coupling of type II antitoxin CopASO. Biochem. Biophs. Res. Commun. 2019, 514, 1122-1127. [CrossRef]

21. Wan, H.; Otsuka, Y.; Gao, Z.; Wei, Y.; Chen, Z.; Masuda, M.; Yonesaki, T.; Zhang, H.; Dong, Y. Structural insights into the inhibition mechanism of bacterial toxin LsoA by bacteriophage antitoxin Dmd. Mol. Microbiol. 2016, 101, 757-769. [CrossRef] [PubMed]

22. Otwinowski, Z.; Minor, W. Processing of X-ray diffraction data collected in oscillation mode. Methods Enzymol. 1997, 276, 307-326. [CrossRef]

23. Sheldrick, G.M. Experimental phasing with SHELXC/D/E: Combining chain tracing with density modification. Acta Crystallogr Sect. D Biol. Crystallogr. 2010, 66, 479-485. [CrossRef]

24. Terwilliger, T.C. Maximum-likelihood density modification. Acta Crystallogr. Sect. D Biol. Crystallogr. 2000, 56, 965-972. [CrossRef] [PubMed]

25. Cowtan, K. The Buccaneer software for automated model building. 1. Tracing protein chains. Acta Crystallogr. D Biol. Crystallogr. 2006, 62, 1002-1011. [CrossRef] [PubMed]

26. Adams, P.D.; Afonine, P.V.; Bunko' czi, G.; Chen, V.B.; Davis, I.W.; Echols, N.; Headd, J.J.; Hung, L.W.; Kapral, G.J.; Grosse-Kunstleve, R.W.; et al. Phenix: A comprehensive Python-based system for macromolecular structure solution. Acta Crystallogr. D Biol. Crystallogr. 2010, 66, 213-221. [CrossRef]

27. Emsley, P.; Lohkamp, B.; Scott, W.; Cowtan, K.D. Features and development of Coot. Acta Crystallogr. Sect. D Biol. Crystallogr. 2010, 66, 486-501. [CrossRef] [PubMed]

28. Chen, V.B.; Arendall, W.B., 3rd; Headd, J.J.; Keedy, D.A.; Immormino, R.M.; Kapral, G.J.; Murray, L.W.; Richardson, J.S.; Richardson, D.C. MolProbity: All-atom structure validation for macromolecular crystallography. Acta Crystallogr. D Biol. Crystallogr. 2010, 66, 12-21. [CrossRef] [PubMed]

29. Aakre, C.D.; Herrou, J.; Phung, T.N.; Perchuk, B.S.; Crosson, S.; Laub, M.T. Evolving new protein-protein in-teraction specificity through promiscuous intermediates. Cell 2015, 163, 594-606. [CrossRef]

30. Kamada, K.; Hanaoka, F. Conformational change in the catalytic site of the ribonuclease YoeB toxin by YefM antitoxin Mol. Cell 2005, 19, 497-509.

31. Liang, Y.; Gao, Z.; Wang, F.; Zhang, Y.; Dong, Y.; Liu, Q. Structural and functional characterization of Escherichia coli toxinantitoxin complex DinJ-YafQ. J. Biol. Chem. 2014, 289, 21191-21202. [CrossRef]

32. Francuski, D.; Saenger, W. Crystal structure of the antitoxin-toxin protein complex RelB-RelE from Methanococcus jannaschii. J. Mol. Biol. 2014, 393, 898-908. [CrossRef] [PubMed]

33. Muthuramalingam, M.; White, J.C.; Murphy, T.; Ames, J.R.; Bourne, C.R. The toxin from a ParDE toxin-antitoxin system found in Pseudomonas aeruginosa offers protection to cells challenged with anti-gyrase antibiotics. Mol. Microbiol. 2018, 111, 441-454. [CrossRef] [PubMed] 
34. Garcia-Rodriguez, G.; Girardin, Y.; Volkov, A.N.; Singh, R.K.; Muruganandam, G.; Van Dyck, J.; Sobott, F.; Versées, W.; Charlier, D.; Loris, R. Entropic pressure controls the oligomerization of the Vibrio cholerae ParD2 antitoxin. Acta Crystallogr. Sect. D Struct. Biol. 2021, 77, 904-920. [CrossRef] [PubMed]

35. Overgaard, M.; Borch, J.; Jørgensen, M.G.; Gerdes, K. Messenger RNA interferase RelE controls relBE transcription by conditional cooperativity. Mol. Microbiol. 2008, 69, 841-857. [CrossRef] [PubMed]

36. Cataudella, I.; Trusina, A.; Sneppen, K.; Gerdes, K.; Mitarai, N. Conditional cooperativity in toxin-antitoxin reg-ulation prevents random toxin activation and promotes fast translational recovery. Nucleic Acids Res. 2012, 40, 6424-6434. [CrossRef] [PubMed]

37. Kim, D.-H.; Kang, S.-M.; Park, S.J.; Jin, C.; Yoon, H.-J.; Lee, B.-J. Functional insights into the Streptococcus pneumoniae HicBA toxin-antitoxin system based on a structural study. Nucleic Acids Res. 2018, 46, 6371-6386. [CrossRef] 